schizophrenia can react in the same way as normal people in similar circumstances. Apathy is not always a symptom of schizophrenia.

At the end of his first letter, Dr Abrahamson said that neither a disease process nor a social model would be sufficient to explain 'institutionalisation'. The introductory chapter of Institutionalism and Schizophrenia (Wing \& Brown, 1970) contains a set of theories, since further developed, concerning the interaction between host and environment.

J. K. WING

MRC Social Psychiatry Unit
Institute of Psychiatry
De Crespigny Park
London SE5 $8 A F$

Reference

WING, J. K. \& Brown, G. (1970) Institutionalism and Schizophrenia. London: Cambridge University Press.

\section{Incest and Anorexia Nervosa: What is the Link?}

SIR: I, and I suspect many other mental health professionals, have been struck by the recent large increase in the number of women referred for assessment and management of the longer-term consequences of sexual abuse in childhood and adolescence.

While every woman's story is unique, one particularly common sequence of events is difficult childhood', sexual assault in adolescence, teenage anorexia nervosa, followed by difficulties in adult sexual adjustment, often with chronic eating disorders. Over the past three months I have seen six women who presented with this personal history.

A review of the standard psychiatric texts failed to clarify the role of sexual assault in the aetiology of female eating disorders. A literature search by Medline and Psych-Info revealed just two significant papers. Openheimer et al (1985) systematically enquired into the sexual histories of 78 women with DSM - III defined anorexia nervosa or bulimia nervosa. Fifty of the 78 subjects reported coersive sexual events, coital and non-coital, prior to the onset of the eating disorder. They concluded, "frequently the sexually molested subject has feelings of inferiority or disgust about her own femininity and sexuality. These may become entangled with concern about her body weight, shape and size ... Do these events play a part in causing the disorders which they precede? At present we cannot be sure".

Sloane \& Leichner (1986) presented five case histories of women presenting with eating disorders after significant sexual assaults. In reviewing the numerous psychodynamic theories of the causation of eating disorders, they observed, "once the factual nature of such material is seriously entertained, certain aspects of anorexia nervosa cease to be as perplexing and can be seen as a rather logical outcome of early sexual trauma". Sloane \& Leichner also comment on the underlying themes of avoidance of sexual feelings, sex role conflicts, concern with sexual activity, and sexual appearance.

Both papers emphasised that the many subjects who are sexually abused do not develop 'apparent' eating disorders and many subjects with eating disorders have 'apparently' not been sexually abused. I have qualified both comments with 'apparent'; the uncertain epidemiological status of both conditions and the massive denial of sexual assault maintained by many victims cautions against dogmatic statements.

If sexual abuse and eating disorders are causally linked, what are the mediators of that link? Based on my recent case series I would offer one explanation. Many female anorexics present with obsessional symptoms. Very often these reflect an underlying insecure, under-confidant and unassertive personality who copes by emotional over-control, the anankastic personality trait.

All the patients I have seen describe 'unhappy childhood' with either (a) dominant, controlling, and destructive mothers and distant or absent fathers who capitulate to the dominant spouse, or (b) dominant but emotionally distant and physically punitive fathers with distant or indulgent mothers. From this early environment the child develops a poor selfimage and learns to suppress all emotional responses, particularly negative ones, to "keep the peace at all costs" by taking all responsibility for any actions against or by it.

When the adolescent is sexually abused, often in a coersive way by a male family member, the intensely painful emotions are handled by the girl as she has learnt to handle all emotions, by introjection and acceptance of unreasonable guilt compounded by fear, anger at herself and the perpetrator, and despair at her inability to share these painful emotions with anyone else. As Sloane \& Leichner observe, certain aspects of anorexia nervosa (guilt, anger, autonomous control, and avoidance of secondary sexual characteristics) become logically understandable as a way of denying the unbearable and guilt-ridden sexual past.

Subsequently, often coincidental with moving away from home to college, nursing or marriage, the burden of keeping silent is lifted and the victim is able to experiment and explore other aspects of relationships with men. Many slowly begin to trust and relax to share intimate feelings. If this trust is abused, then 
the young adults may well present with a decompensated eating disorder or significant affective symptoms, particularly anxiety and depression. If the trust is nurtured then deeper relationships are established, frequently leading to sexual expression. All of the series I have seen described that this 'first proper' sexual relationship provoked in an intense way the now well-suppressed painful memories of earlier sexual activity, causing the victim to decompensate again with recurrent eating disorders, affective symptoms, or marital or sexual adjustment problems.

I propose a causal link between premorbid personality features, sexual assault in adolescence, subsequent anorexia nervosa, and later difficulties in sexual adjustment.

\section{The Princess of Wales RAF Hospital}

D. M. HAMBIDGE

Ely

Cambridgeshire CB6 IDN

\section{Reforences}

Openheimer, R., Howells, K., Palmer, R. L. \& Challener, D. A (1985) Adverse sexual experience in childhood and clinical eating disorders: a preliminary description. Journal of Psychiatric Research, 9, 357-361.

SLOANe, G. \& LeichNer, P. (1986) Is there a relationship between sexual abuse or incest and eating disorders? Canadian Journal of Psychiatry, 31, 656-660.

\section{Diethylpropion and Psychosis}

SIR: Diethylpropion hydrochloride, an appetite suppressant related to the amphetamines and introduced in 1963, is a rare cause of psychosis (Fookes, 1976; Carney \& Harris, 1979). Thus, from January 1964 until July 1986, only 5 cases of "psychosis" and 12 other cases with diagnoses suggestive of psychosis were reported to the Committee of Safety of Medicines. That the disorder may not be rare is suggested by the two in-patients described below, referred to me over a 3-year period.

Case Reports: (i) An obese married housewife aged $\mathbf{4 0}$ was admitted after a month of complaining of fears that her first son would die through the "evil eye" of her mother-in-law, "personality change", unreality-feelings, depression, anergia, and poor concentration. The son suffered from cystic fibrosis, and she feared that if she took her second son to the same hospital, her first son would die and that she herself had only one year to live. Her husband reported that she alternated between amorous hilarity and depressive frigidity. She initially denied drug and alcohol-taking or previous breakdown, but admitted that her mother had had a depressive illness. It transpired that for many years her GP had prescribed diethylpropion hydrochloride for obesity in herself and her husband, which she had taken in therapeutic doses without losing weight. (ii) An obese 33-year-old married housewife was admitted with a 3-year history of complaints of depression, anxiety, and fears that others disliked her, made hurtful references to her, and were influencing her by telepathy. She heard a policeman say to her "don't be scared - it's a cross between two evils" and thought others believed that she had the "evil eye". Happily married, she was described as a welladjusted, adequate person with no history of mental illness or drug or alcohol abuse. It transpired that she had been taking therapeutic doses of diethypropion, prescribed by a doctor at a slimming clinic.

In each case the diagnosis was confirmed by urinary testing for amphetamine-like substances. These tests also proved valuable in monitoring compliance during the follow-up period.

Both patients were typical, obese, middle-class, North London, Jewish housewives. Both were referred by their GPs for depression and up to then had concealed their paranoid delusions and drugdependence. They eventually owned up to taking diethylpropion in therapeutic doses, medically prescribed for obesity, over long periods. Their symptoms, consistent with paraphrenia, rapidly responded to chlorpromazine and withdrawal of diethylpropion. Over a 6-month follow-up period neither relapsed. The setting for the development of these psychoses was extraordinarily mundane, almost banal, with none of the near-magical symbolism surrounding the abnormal experiences of the acute schizophrenic. Moreover, these patients were female and somewhat older than the average age of first onset of schizophrenia. Psychoses during the ingestion and following the withdrawal of amphetamines (a related compound-both are sympathomimetic amines) have been recorded (Mayer-Gross et al, 1969).

Prescribing of diethylpropion has markedly diminished from 1567 million prescriptions in 1979 to 388 million in 1985 (Department of Health and Social Security, Statistics and Research Division, personal communication). This decrease may make the condition more difficult to diagnose, as doctors are less likely to think of it in the first place. Yet this psychosis, which mimics schizophrenia, is eminently treatable provided the possibility is borne in mind. The incidence of these reactions may be expected to vary with fashions in slimming. It is therefore surprising that whereas, over recent years, weightreduction has become more popular, prescribing of anti-obesity drugs has diminished. Possibly other ways of slimming, such as diet and exercise, have become more fashionable.

All anti-obesity drugs, apart from bulking agents like methyl cellulose, may be expected to cause psychological ill-effects and tolerance. However, 